\title{
Goodbye Nicky hello Goldie - exploring the opportunities for transitioning tobacco farmers into cannabis production in Malawi
}

\author{
Linda Sowoya, Chifundo Akamwaza, Austin Mathews Matola and Axel Klein
}

\begin{abstract}
Purpose - The purpose of this paper is to illustrate the opportunities for tobacco farmers in Malawi from diversifying to cannabis, and the potential benefits for reducing deforestation by producing a cannabis based alternative fuel. It further argues that there are tensions between the conflicting objectives of the Framework Convention on Tobacco Control and the Single Convention on Narcotic Drugs.
\end{abstract}

Design/methodology/approach - Field interviews were conducted with cannabis farmers, traders and sellers in different parts of Malawi.

Findings - The findings of this study show that there are opportunities for cannabis farmers but they have been blocked by legal impediments. Now that legislative reform have made cannabis cultivation possible, farmers need support in developing products.

Research limitations/implications - Any attempt to provide a precise assessment of the cannabis market in Malawi is constrained by the criminalised status of the product. The suitability of cannabis briquettes as an fuel has yet to be trialled in Malawi.

Social implications - There is an urgent need to revise the drug control conventions to address environmental degradation and deforestation.

Originality/value - The linkage between tobacco farming, deforestation and desertification in Malawi has not been made. This is the first time that hemp has been suggested as an alternative crop for farmers and as a solution to deforestation.

Keywords Malawi, Rural development, Cannabis cultivation, Hemp

Paper type Research paper

$\mathrm{T}$ he 21st century has seen dramatic innovations in the delivery mechanisms for cannabis. Rapid advances in vaporising technology, the refinement of cannabis oils and edibles, have transformed the cannabis landscape. Up until then, most cannabis consumers in Europe, at least, would combine their cannabis with tobacco, a possible etymological origin of the term "joint". Both plant-based substances have been on diametrically opposed trajectories. For most of the 20th century, cannabis was denounced as the "devil's weed", whereas tobacco was celebrated as a symbol of the good life. Things have changed dramatically, as the medical consensus attributes no benefits but ample evidence of health harms to tobacco, while conversely, there is increasing evidence for the potential therapeutic benefits of cannabis.

Exciting though this situation is for growers and pharmaceutical companies in high-income countries at the cutting edge of policy change; it causes considerable difficulties for the farmers in developing countries. Almost invariably, the takers not makers of international
(Information about the authors can be found at the end of this article.)

Received 15 April 2020

Revised 28 April 2020

Accepted 4 May 2020

(C) Linda Sowoya,

Chifundo Akamwaza,

Austin Mathews Matola and Axel Klein. Published by Emerald

Publishing Limited. This article is published under the Creative Commons Attribution (CC BY 4.0) licence. Anyone may reproduce, distribute, translate and create derivative works of this article (for both commercial and

non-commercial purposes), subject to full attribution to the original publication and authors. The full terms of this licence may be seen at: http://creativecommons. org/licences/by/4.0/legalcode

Funding: This research was provided by the Foundation for a Smoke Free World.

Expression of concern: The publisher of the journal Drugs and Alcohol Today is issuing an Expression of concern for the following article Sowoya, L., Akamwaza, C., Matola, A.M. and Klein, A. (2020), "Goodbye Nicky hello Goldie - exploring the opportunities for transitioning tobacco farmers into cannabis production in Malawi", published in Drugs and Alcohol Today, Vol. 20 No. 3, pp. 295-303, to inform readers that credible concerns have been raised regarding the editorial process for this article. An investigation is ongoing and is currently unresolved. Further information will be provided by Drugs and Alcohol Today as it becomes available. 
rules, are left with outmoded legislative and production systems and lose out on any advantage accruing to early adaptors. They are particularly exposed to the restrictions imposed by international treaties, where these are monitored by transnational bureaucracies and enforced by powerful development cooperation partners. As a consequence, treaties that were formulated to further human well-being, have the unintended consequence of causing severe economic and political harm to some of the most vulnerable and voiceless populations.

Of particular concern is how two sets of international legislation, the 2003 Framework Convention on Tobacco Control (FCTC) and the 1961 Single Convention on Narcotic Drugs are impacting on rural communities in Malawi, a landlocked country of 18 million people in Southern Africa. This paper draws on interviews with farmers in Lilongwe and Kasungu districts in Malawi and with participants in the cannabis economy in Lilongwe between September - November 2018 to discuss tensions between the treaty system and highlight the need for lifting the restrictions on rural development imposed by some of the provisions in the Single Convention.

\section{Tobacco and cannabis: contrasting approaches to containing health harms}

The 2003 FCTC is the first international public health treaty to be adopted under the World Health Organisation (WHO) Article 19 "to protect present and future generations from the devastating health, social, environmental and economic consequences of tobacco consumption and exposure to tobacco smoke by providing a framework for tobacco control measures" (WHO, 2003, p. 5). States that accede to the treaty are obliged to implement a range of controls on the production and distribution of tobacco products, such as regulating advertising and packaging of tobacco products, imposing restriction on the supply to tobacco and protection of third parties from tobacco smoke.

Decades of research had established tobacco use, particularly the practice of cigarette smoking, as the second leading cause of premature death in the world (Murray and Lopez, 1997). According to the WHO (WHO, 2019), the "tobacco epidemic is one of the biggest public health threats the world has ever faced, killing more than 8 million people a year around the world [...]. [by causing] [...] cardiovascular and respiratory diseases, including coronary heart disease and lung cancer". Both cause of harm and the scale of the impact had been well established before state parties were invited to adopt control measures on a voluntary basis.

The wording of the treaty leaves state parties considerable room for manoeuvre. Pricing policies, for example, are recognised as an "Effective and important means of reducing tobacco consumption" so parties "should take account of its national health objectives" when adopting tax policies on tobacco products. Minors are to be protected by bans on sweets and toys that are in the form of tobacco products and by ensuring that vending machines are not accessible. But the treaty does not require states' parties to prohibit tobacco sales to minors below a uniform age, providing only that each state party shall "prohibit the sales of tobacco products to persons under the age set by domestic law, national law, or eighteen" (Article 16.1).

The intention behind the convention is to provide a framework or platform on which parties can continue negotiating tobacco control measures (Fidler, 2003). It is designed to establish a process by which participating states can work together in introducing measures to reduce tobacco consumption.

In reducing tobacco-related harms, the FCTC places the potential tobacco consumer at the centre. The first guiding principle adopted is therefore for every person to be "informed of the health consequences, addictive nature and mortal threat posed by tobacco consumption". A list of measures detailing education, communication, training and public 
awareness is detailed under Article 12 and efforts by tobacco industry, to undermine their intent through advertising and promotion, curtailed under Article 13.

Contrast this approach with the explanatory rationale of the 1961 Single Convention on Narcotic Drugs "that addiction to narcotic drugs constitutes a serious evil for the individual and is fraught with social and economic danger to mankind". Without having conducted any scientific assessment of the harm of cannabis, which is included with opium and coca in the provisions, the convention restricts the production or importation to holders of a licence from a designated government agency. It then stipulates that "parties shall not permit the possession of drugs except under legal authority" (Article 33) and lays down how infractions are to be dealt with. The unauthorised cultivation, preparation or possession of cannabis "shall be punishable offences when committed intentionally, and that serious offences shall be liable to adequate punishment particularly by imprisonment or other penalties of deprivation of liberty".

Non-compliance with the provisions of the FCTC continues to hold back public health gains, but the WHO has no system of incentives or sanctions in place to speed up the process. Countries whose governments are not abiding by their provision under the Single Conventions, on the other hand, risk serious consequences. Each year the US State Department publishes an International Narcotics Control Strategy Report that assesses countries' performance in meeting their drug control obligations. Where these are deemed to be falling short, punitive measures may be imposed, ranging from the withdrawal of foreign assistance to withdrawing landing rights from national carriers or suspending international banking services.

The majority of African countries have therefore signed up to the Single Convention and all have enacted its provisions, so that cannabis is illegal in every single African jurisdiction. Even though there is illegal cultivation (UNODC, 2019), it is to supply local markets. Only Morocco continues to send out cannabis on significant scale but has to contend with the dramatic import substitution in its European export markets. Across the continent then, cannabis has long ceased to play a significant role in the formal sector, even though it may provide an economic niche of growing significance (Carrier and Klantschnig, 2016, 2018).

To summarise, the international prohibition of cannabis was based on moral concerns, without a scientific assessment of harms or benefits, focussed on reducing supply and empowering the state. The tobacco convention, by contrast, prioritised reducing demand, protected the individual and was based on an extensive scientific assessment. From the farmer's perspective, both treaties have the same objective - to put an end to their business.

\section{Farmers caught between two conventions}

In recognition of the farmers' dilemma, Article 17 of the FCTC states the need of providing an "economically viable alternative [...] for tobacco workers, growers and, as the case may be, individual sellers". (WHO, 2003, Article 17). No further guidance is given and in keeping with the strict division of labour within international bureaucracy, such responsibility is passed on to the "competent international and regional intergovernmental organizations". The remit of the WHO extends to health, so that the need for environmental protection is only mentioned in passing (WHO, 2003, Article 18).

The situation is particularly urgent for Malawi, which has been described as one of the most tobacco dependent countries in the world. An estimated $20 \%$ of smallholder farmers are involved in tobacco production (Chirwa, 2011), generating 50\% of the country's foreign exchange earnings (BACl, 2016). In the early post-independence era, tobacco production in Malawi was the preserve of large estates supported by the Agricultural Development and Marketing Corporation. But under the World Bank-led Structural Adjustment Program in 
1992, the market was opened to smallholders. The total amount of land used for tobacco production grew from 41,763 ha in 1961 to 112,734 ha in 2016.

Economic benefits for rural communities came at the cost of deforestation, land and soil degradation, water pollution and ecosystem disruptions (Lecours et al., 2012). Whereas the costs of the environmental degradation that have accompanied economic growth are glossed over in macro-economic strategy papers (World Bank, 2017); they are apparent and alarming at village level. Deforestation to clear land for farming and to obtain firewood for tobacco curing has contributed significantly to the progressive savannafication of large parts of Lilongwe and Kasungu districts (Klein et al., 2019).

This spiralling, self-perpetuating process of resource depletion is recognisable in the reported scarcity of water owing to run-off and in the need for increasing amounts of fertiliser because of declining soil productivity, a consequence of erosion and intensive farming. If this continues, many rural communities will be unable to support themselves in the near future. Though it has been claimed that there are more profitable alternatives to tobacco (Makoka et al., 2017), farmers interviewed in Lilongwe and Kasungu district explained that the key advantages of growing tobacco were the availability of credit and technical support from extension workers and a relatively functioning market system (Klein et al., 2019).

Though farmers were happy to experiment with other crops such as soya, groundnuts, onions or cassava, they would often return to tobacco. Growing the more perishable crops was always risky, because transport could be difficult to organise after harvest. And for any crop, it was difficult to guarantee that prices could be maintained for several years running. With tobacco, however, demand was strong, even when prices were declining.

\section{Cannabis in Malawi}

One of the few promising alternatives, however is cannabis, known as chamba in Malawi. It was probably first introduced by traders along long-distance overland trading trails stretching to the Swahili coast where it had been brought by traders from the Indian subcontinent (du Toit, 1980). Chichewa speaking farmers included the plant into their agricultural production cycle, produced different cultivars, including one of the best known from Sub-Saharan Africa, Malawi Gold and integrated cannabis into culture and ritual. Europeans travelling across what today is Malawi, in the late 19th century, reported that religious functionaries (described as prophetesses or witch doctors) were wearing cannabis leaves at ceremonies and how cannabis was burned at funerals (Duval, 2019, p. 109). Informants interviewed in the early 20th century were cultivating several cannabis varieties including one for oil seed and distinguished between different grades of cannabis inflorescences harvested for smoking (Duvall, 2019, p. 76).

Following military occupation and absorption into the British Central Africa Protectorate in 1891, the country was subjected to a new regime and economic interests. Though tobacco farming was introduced as a cash crop, there was little use for hemp products. Colonial controls on cannabis came early and were strict. It was the white minority government of South Africa, which pushed for the inclusion of cannabis as one of the substances to be internationally controlled under the Opium Convention of 1925 (Duvall, 2019, 2016). The first independent government of Hastings Kamuzu Banda, the Prime Minister and later President of Malawi from 1964-1994, further tightened the provisions of the Dangerous Drugs Act. In Malawi as in the rest of the world, the global war on drugs pushed cannabis underground and into the margins.

In the highlands rising from the Dwangwa river in the northern parts of Kasungu district lies one of Malawi's centres of cannabis cultivation. A remote area with no visible sign of government services or infrastructure save a few primacy school blocks, suffers from decades of neglect. With no paved roads connecting the district, farmers are at a severe 
disadvantage when raising crops such as maize, soybean or even tobacco. Getting produce to market is expensive and slow, so the farmers run the risk of their produce perishing in the farmyard before the trucks arrive to collect it.

One way of turning this neglect by the authorities around, is by producing illicit products. Farmers have therefore set up farms in hidden valleys or on patches of land deep inside the nearby Nkhotakota game reserve. They prospered in the early 2000 s when cannabis prices ranged from MK30,000 to MK35,000 for a 20 litres bucket [1]. From about 2010, competing production from other districts began pushing prices down to MK15,000. At the same time, a new management company, African Parks, took over the running of the game reserve. Illicit cultivation was no longer tolerated, crops were destroyed and farmers were arrested. Many people who were once growing cannabis then moved into transportation and distribution (Interviews, Hanyezi, November 2018).

Though the work is potentially dangerous and backbreaking, it is also more lucrative. Fieldwork conducted in Lilongwe, the capital, during October 2018, established that cannabis of good quality was sold for as much as MK40,000 per kilogram and even the poorest grades were selling for MK8,000. In the absence of epidemiological data on consumption patterns in Malawi, it is impossible to assess the size of the market. Interestingly, there is a small but thriving Rastafarian community, who are open about their support for cannabis even while they remain discrete in their actual consumption.

Interviews with a sample of six Rastafarians in Lilongwe revealed that all of them were regular cannabis consumers, but only half were involved in growing and another two in selling cannabis. A couple reported having become involved in hemp use from a tender age through their parents. They reported smoking between 3-5 joints a day, each made up of between 1-2 grams of hemp leaves.

Just as important were the other uses that hemp products were put to. There is a large market in hair care products made from cannabis seeds, which is used widely outside of the Rastafarian community. To get a notion of the scale and further potential of the industry, it is worth quoting one producer who reported to be using between $60-100 \mathrm{~kg}$ of hemp seed per year, at a price of MK25,000 per kilogram. Though there is an interest in further uses of cannabis for packaging, textiles, medications, oils and edibles, these products are only poorly developed at present, largely because of the legal obstacles.

In the first formulation of the Dangerous Drugs Act in 1955, the colonial government failed to distinguish between different types of cannabis. This is not surprising, given that the importance of tetrahydrocannabinol (THC) as the psychoactive material had yet to be discovered. Subsequent amendments failed to rectify this shortcoming, thereby further impeding the growth of any potential industrial hemp industry. At the same time, penalties for possession offences were raised for "a fine not exceeding one hundred dollars for each ounce of ganja (sic) which the Resident Magistrate is satisfied is the subject matter of the offence" or imprisonment "for a term not exceeding three years" or both. (Dangerous Drugs Act, 1994).

\section{Legal reform and the potential of cannabis production in Malawi}

On 27th of February 2020, a new Cannabis Regulation Act came into force creating for the first time opportunities for the legal cultivation of cannabis for medicinal and industrial purposes. According to Kondwani Nankhumwa, the Minister for Agriculture, this is an attempt to help diversify and boost Malawi's economy at a time when global tobacco consumption is dwindling (Sambalikagwa, 2020). Malawi is now poised to catch up with some of her neighbours in Southern Africa. Lesotho, Zimbabwe and Zambia have already established cannabis production and even attracted foreign investment. South Africa has gone further still by decriminalising recreational cannabis use and small-scale cultivation. 
To oversee the industry, a new agency the Malawi Cannabis Regulatory Authority has been created. Two companies were involved in the field trials running prior to the reform and proving the concept of producing commercial cannabis products. Both are now moving to the commercial development of a range of products, the most promising of which in the short term being the medical and health-care markets. IKAROS is now promoting its cannabidiol (CBD) oil and extracts, produced without the use of herbicides and pesticides in the "the heart of Malawi". In 2018, the Critical Review by the WHO's Expert Committee on Drug Dependence found that CBD had been demonstrated as an effective treatment for epilepsy in several clinical trials, had a good safety profile and no abuse or dependence potential. It then recommended that CBD preparations be excluded from the international controls obtaining for other cannabis products (WHO, 2018). As several countries have already modified their legislation to allow for the sale of CBD products, there is an expectation among producers in Africa and Caribbean to capitalise on production methods and branding and export to these markets.

There are also opportunities for products aimed initially at least, for the domestic market. There are well known uses for hemp fibre in textile production and for oil from hempseed for food and livestock feed. But there are two applications that hold high potential for meeting the particular needs of Malawi today. The first is promoted by INVEGROW, a Malawian company producing a range of industrial and medical cannabis products. One of these is hempcrete, made from the hemp hurds or shives, a waste product from processing hemp fibres when mixed with lime. This product has strong insulating qualities and lacking the brittleness of concrete, makes a good construction material.

By African standards, the country has been urbanising at a moderate rate, with annual rates of 3.7\%-3.9\% over 1998-2009 and with an estimated $16 \%$ of the population living in urban areas (World Bank, 2016). But even at this relatively low pace, the trend is putting great stress on the natural resource base. In Malawi, the main construction material is clay bricks made by artisanal producers in wood-fired kilns. It has been estimated that at current rates of urbanisation, 1.7 billion bricks will be needed annually, which in turn will require 850,000 tons of fuelwood (Klein et al., 2019). This is adding to the already unsustainable pressure on national wood reserves.

Even more urgent is the need for alternative fuel sources. At present, only $11 \%$ of households have access to electricity (World Bank, 2020), so that even in urban areas firewood or charcoal are used for cooking. The Ministry of Natural Resources, Energy and Mining has calculated that 2.35 million $\mathrm{m}^{3}$ of wet wood will be required to meet this demand, the equivalent of more than 25,000 ha of woodland. At current levels of use, charcoal demand is expected to reach 606,000 tons/year by 2023 , which is totally unsustainable (Government of Malawi [GoM], 2017).

Efforts are under way to distribute specially adapted stoves that are more fuel efficient, as well as solar panels. Yet, at current rates of distributions, other initiatives are needed to conserve the remaining woodlands. It is therefore worth considering alternative fuel products that can be used in traditional settings. Slow burning fuel briquets made from the waste products from the timber industry have for long been popular in Europe and North America. More recently, there has been an increasing number of briquets produced from hemp or cannabis strains low in THC.

Here lies a real opportunity for smallholder farmers in Malawi, but potentially in other parts of rural Africa as well. Hemp is optimal because it is fast growing and produces a large amount of biomass for processing. The raw material can be easily harvested, can be stored for extensive periods and then be taken to regional market towns where processing plants with the relatively simple technology can be set up. The briquettes could then be collected by middlemen for distribution in the cities and/or used regionally.

Given the rapid rate of deforestation in Malawi and other parts of Africa, when the value of tree conservation is increasingly recognised as indispensable for flood control, to soil 
conservation and carbon sequestration, the expansion of the industrial cannabis industry is a matter of greatest urgency.

\section{Discussion}

The new legislation has thrown a lifeline to the Malawian farming sector that is reeling under the impact of falling tobacco prices and the sharp degradation of the natural environment. Smallholder farmers, however, are unlikely to respond without clear guidance and the involvement of industrial partners. In Malawi, farmers are severely affected by the poor performance of product markets and therefore like to produce for end buyers, who guarantee to take their produce off them after harvest. They also like to have access to knowhow, seeds and other inputs. Yet, there are only a couple of companies in the cannabis market at the moment and even these are in the early stages of development.

Much will depend on the work of the Cannabis Regulatory Authority in developing guidance and issuing licences. The donor community will also be looked to in supporting the experimental cultivation of cannabis crops and processing. But the greatest potential for initiating transformation lies with the tobacco-producing companies that have the management capacity, technical skill and financial reserves for developing a nascent industry.

At the same time, the obstacles remain formidable. Cannabis, even in its medical form, is not a commodity that is easily traded. This owes much to the international agreements that prohibited the cultivation and distribution of the plant. At the root is the way in which the 1961 Single Convention has been laid out. It "represented a moment when the multilateral framework shifted away from regulation and introduced a more prohibitive ethos" (BewleyTaylor and Jelsma, 2011). At the time of drafting the Convention, little was known about cannabis, THC had not yet been discovered and environmental concerns were low on the agenda. The meeting was strongly influenced by the US delegation, led by Harry J. Anslinger, with his deep commitment to drug prohibition.

Though the USA has since backed away from the war on drugs approach that it once championed, the system is set up and reform appears difficult. At the Commission on Narcotic Drugs, the relevant UN agency, it is far easier to extend controls to new substances than lift restrictions already in place. Indirectly, the provisions intended to protect mankind from the evil of addiction, are now placing an obstacle in the way of small farmers in Southern Africa to transition from tobacco.

\section{Conclusion}

The difficulties faced by African farmers throw into relief some of the flaws in treaties that are formulated in response to the very particular concerns of a politically dominant interest group, but have application globally. To better safeguard the interest of vulnerable groups without representation, international treaties at minimum should ensure that treaty provisions are:

- based on solid evidence;

- provide an iterative policy framework where measures can grow organically against need;

- avoid punitive measures against stigmatised minorities; and

- take cognisance of other international treaties that will impact on it.

The approach of the FCTC is far more congenial to adaptation to local need and allows signatory states considerable room for manouver. Yet, care should be taken that the process does not lead to an ideological impasse where tobacco prohibition becomes the overriding objective.

Malawi, meanwhile, is facing stark economic challenges owing to the drastic decline in demand for its main export crop. Finding a new dynamism for its economy is urgent and the 
expansion of cannabis production could prove a much-needed stimulus. Getting tobacco farmers to transition from tobacco to cannabis, could also address some of the most pressing environmental problems the country is facing. If no steps are taken to arrest the destruction of what remains of Malawi's miombe forests, then large tracts of currently productive agricultural land will be lost within the coming years.

As a small, low-income country, Malawi has been looking overseas for guidance on what crops to grow, what policies to adapt and in the crafting of legislation. Being made to abandon its indigenous chamba for burley tobacco has extracted a high price. The current legislation opens the way for using cannabis in the construction and health-care sector. More input is needed from development partners and investors to realise the transformational potential of the cannabis-briquette-based fuel alternative.

But to optimise the brand that was created by previous generations of farmers, cultivating the sativa strain that is known as Malawi Gold, reforms need to go further. If the current control system is resistant to removing cannabis from the schedule of controlled substances, then Malawi and her regional partners should consider joining other likeminded nations in formulating a new set of agreements that is more responsive to changes in the evidence base, holds the needs of humans at their centre and takes account of pressing global issues such as climate change and desertification.

\section{Note}

1. Over the past two years, the Malawi Kwacha has fluctuated between 800-1,000 per £1.

\section{References}

BACl (2016), World Trade Database by CEPII, (2016), Base Pour L'Analyse du Commerce International, Paris, (accessed 1 November 2018).

Bewley-Taylor, D. and Jelsma, M. (2011), "Regime change: re-visiting the 1961 single convention on narcotic drugs", International Journal of Drug Policy, Vol. 23 No. 1, pp. $72-81$.

Carrier, N. and Klantschnig, G. (2016), "Illicit livelihoods: drug crops and development in Africa", Review of African Political Economy, Vol. 43 No. 148, pp. 174-189.

Carrier, N. and Klantschnig, G. (2018), "Quasilegality: khat, cannabis and Africa's drug laws", Third World Quarterly, Vol. 39 No. 2, pp. 350-365.

Chirwa, E.W. and Klantschnig, G. (2011), Analysis of the Tobacco Industry in Malawi, United Nations Conference On Trade And Development.

Dangerous Drugs Act (1994), available at: https://moj.gov.jm/sites/default/files/laws/The\%20Dangerous\% 20Drugs\%20Act.pdf (accessed 4 March 2020).

Du Toit, B. (1980), Cannabis in Africa. A Survey of Its Distribution in Africa, and a Study of Canabis Use and Users in Multietnic [Sic] South Africa, Balkema, Rotterdam.

Duval, C. (2019), The African Roots of Marijuana, Duke University Press, London.

Food and Agriculture Organization (FAO) (2020), "Food and agriculture organization (FAO) of the United Nations. Review of food and agricultural policies in Malawi", Country Report 2014. Rome 2015, available at: www.fao.org/fileadmin/templates/mafap/documents/Malawi/MCR_May2015.pdf (accessed 28 February 2019).

Government of Malawi (GoM) (2017), "National charcoal strategy 2017-2027. Lilongwe, Malawi: Ministry of Natural Resources, Energy and Mining".

Klein, A., Kamwaza, C., Chisuso, D., Nyirenda, M.,C. and Kayange, E. (2019), "Rural perspectives on alternatives to tobacco farming and environmental degradation in Malawi", FSFW Working Paper No. 1 Agriculture and Livelihoods. New York: Foundation for a Smokefree World, available at: www. smokefreeworld.org/wp-content/uploads/2020/01/WPS-1.pdf (accessed 3 Feburary 2020).

Lecours, N., Almeida, G.E.G., Abdallah, J.M. and Novotny, T.E. (2012), "Environmental health impacts of tobacco farming: a review of the literature", Tobacco Control, Vol. 21 No. 2, pp. 191-196. 
Makoka, D., Drope, J., Appau, A., et al. (2017), "Costs, revenues and profits: an economic analysis of smallholder tobacco farmer livelihoods in Malawi", Tobacco Control, Vol. 26 No. 6, pp. 634-640, doi: 10.1136/tobaccocontrol-2016-053022.

Murray, C.J. and Lopez, A.D. (1997), "Alternative projections of mortality and disability by cause 19902020: global burden of disease study", The Lancet, Vol. 349 No. 9064, pp. 1498-1504.

Sambalikagwa, L., (2020), "Malwi parliament passes cannabis bill", Malawi24, available at: https:// malawi24.com/2020/02/27/malawi-parliament-passes-cannabis-bill/ (accessed 10 April 2020).

UNODC (2019), World Drug Report, United Nations Office on Drugs and Crime, Vienna.

WHO (2003), WHO Framework Convention on Tobacco Control, World Health Organization, Geneva.

WHO (2018), CANNABIDIOL (CBD) Critical Review Report Expert Committee on Drug Dependence Fortieth Meeting Geneva, 4-7 June 2018, World Health Organization, Geneva.

WHO (2019), Tobacco, available at: www.who.int/news-room/fact-sheets/detail/tobacco (accessed 6 April 2020).

World Bank (2016), Malawi Urbanization Review Leveraging Urbanization for National Growth and Development, World Bank, Washington, DC.

World Bank (2017), Malawi Economic Monitor: Harnessing the Urban Economy, World Bank, Washington, DC.

World Bank (2020), Sustainable Energy for All (SE4ALL) database, World Bank, Washington, DC, available at: https://data. worldbank.org/indicator/EG.ELC.ACCS.ZS?locations=CN

\section{Further reading}

Drope, J., Makoka, D., Lencucha, R. and Appau, A. (2016), Farm-Level Economics of Tobacco Production in Malawi, Centre for Agricultural Research and Development, Lilongwe, Malawi, available at: www.cancer.org/content/dam/cancer-org/research/economic-and-healthy-policy/farm-level-economicsof-tobacco-production-in-malawi-full-report.pdf (accessed 27 February 2019).

Filder, D. (2003), "World health organisation's framework convention for tobacco control", Insights: American Society of International Law, Vol. 8, p. 3.

Jaffee S. Malawi's Tobacco Sector (2020), "Jaffee S. Malawi's tobacco sector: standing on one strong leg is better than on none", Africa Region Working Paper Series; No 55, World Bank, Washington, DC, available at: http://documents.worldbank.org/curated/en/505031468757241265/Malawis-tobaccosector-standing-on-one-strong-leg-is-better-than-on-none (accessed 27 February 2019).

Negri, M. and Porto, G.G. (2008), Burley Tobacco Clubs in Malawi: Nonmarket Institutions for Exports. The World Bank Development Research Group; Safia.

\section{Author affiliations}

Linda Sowoya, Chifundo Akamwaza and Austin Mathews Matola are all based at the Lilongwe University of Agriculture and Natural Resources, Lilongwe, Malawi.

Axel Klein is based at the Centre for Biocultural Diversity, University of Kent, Canterbury, UK.

\section{Corresponding author}

Axel Klein can be contacted at: axelcklein28@gmail.com

For instructions on how to order reprints of this article, please visit our website: www.emeraldgrouppublishing.com/licensing/reprints.htm

Or contact us for further details: permissions@emeraldinsight.com 